\title{
High electrochemical seawater desalination performance enabled by an iodide redox electrolyte paired with a sodium superionic conductor
}

\author{
J. Lee, ${ }^{a, b, c}$ P. Srimuk, ${ }^{a, b}$ R. L. Zornitta, ${ }^{a, d}$ \\ M. Aslan, ${ }^{a}$ B. L. Mehdi, ${ }^{c}$ and V. Presser ${ }^{a, b},{ }^{*}$
}

a INM - Leibniz Institute for New Materials, Campus D2 2, 66123 Saarbrücken, Germany

b Department of Materials Science and Engineering, Saarland University, Campus D2 2, 66123 Saarbrücken, Germany

c University of Liverpool, School of Engineering, 514 Brodie Hall, L69 3GQ, Liverpool, United Kingdom

d Department of Chemical Engineering, Federal University of São Carlos, 13565-905 São Carlos, Brazil

Number of figures: $\quad 5$

Number of tables: $\quad 1$

Number of pages: $\quad 5$ 


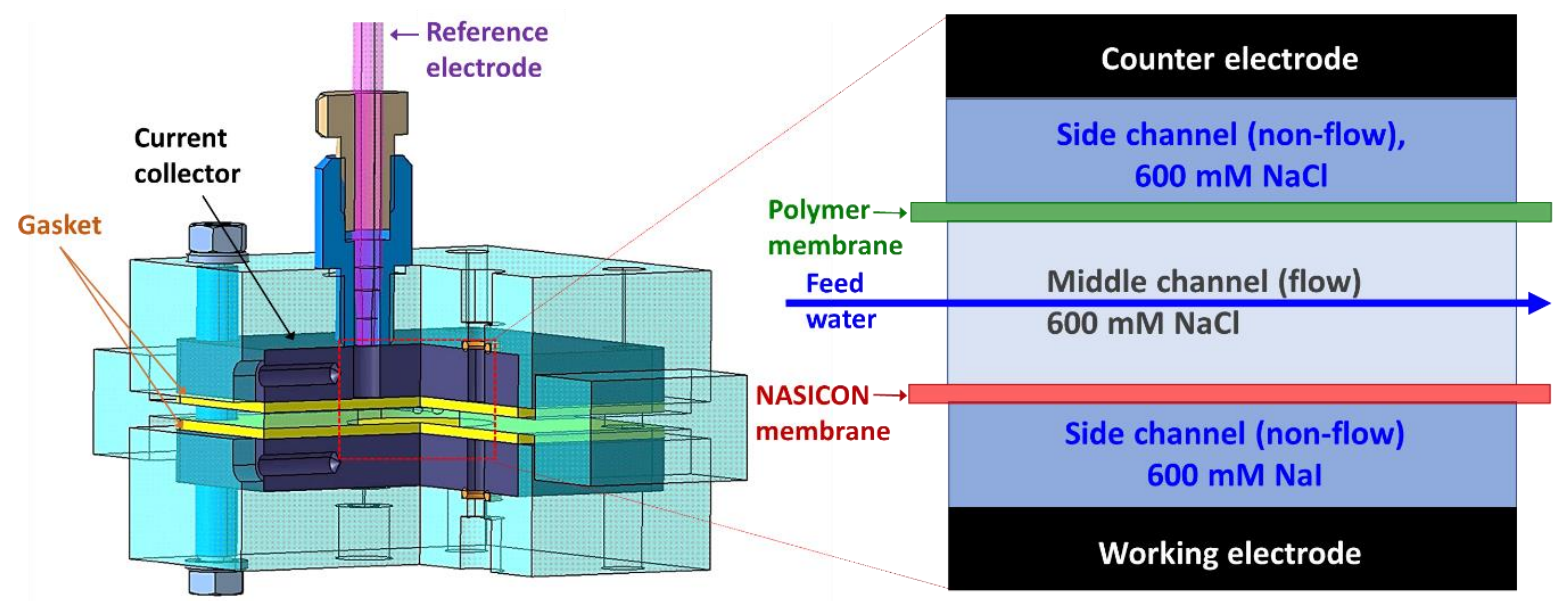

Figure S1: Scheme of the desalination cell. The feedwater stream is subject to the desalination process and flows across the cell, while the electrolytes contained within the sidechannels does not flow and provides a local chemical environment for the activated carbon electrodes.

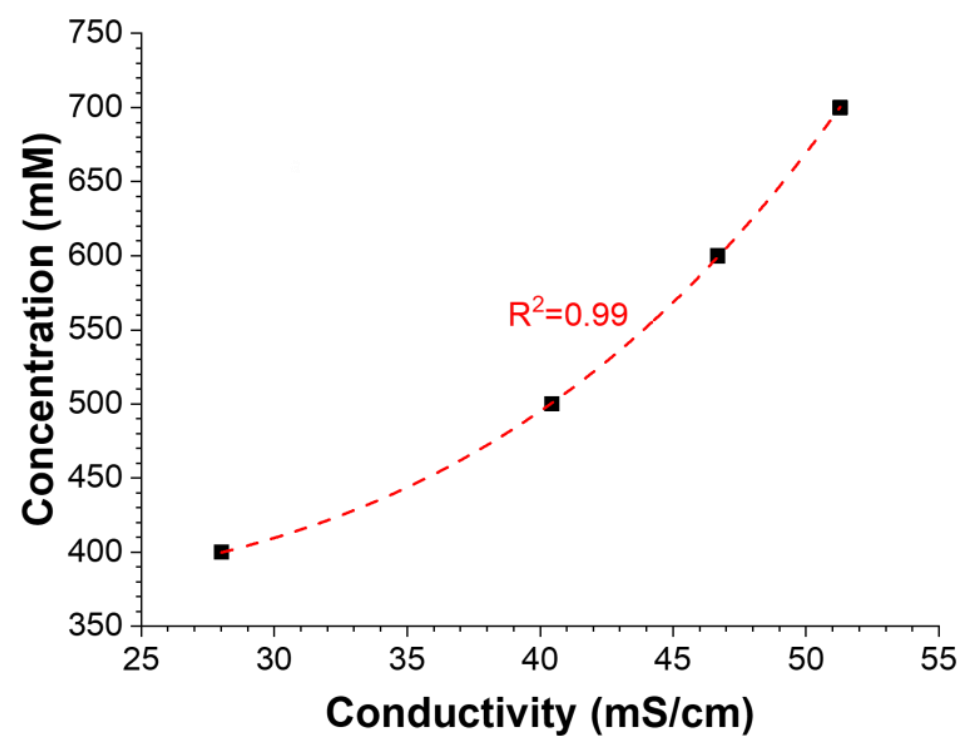

Figure S2: Calibration curve based on the measured conductivity values from $400 \mathrm{mM}$ to $700 \mathrm{mM}$ aqueous $\mathrm{NaCl}$ solutions. 

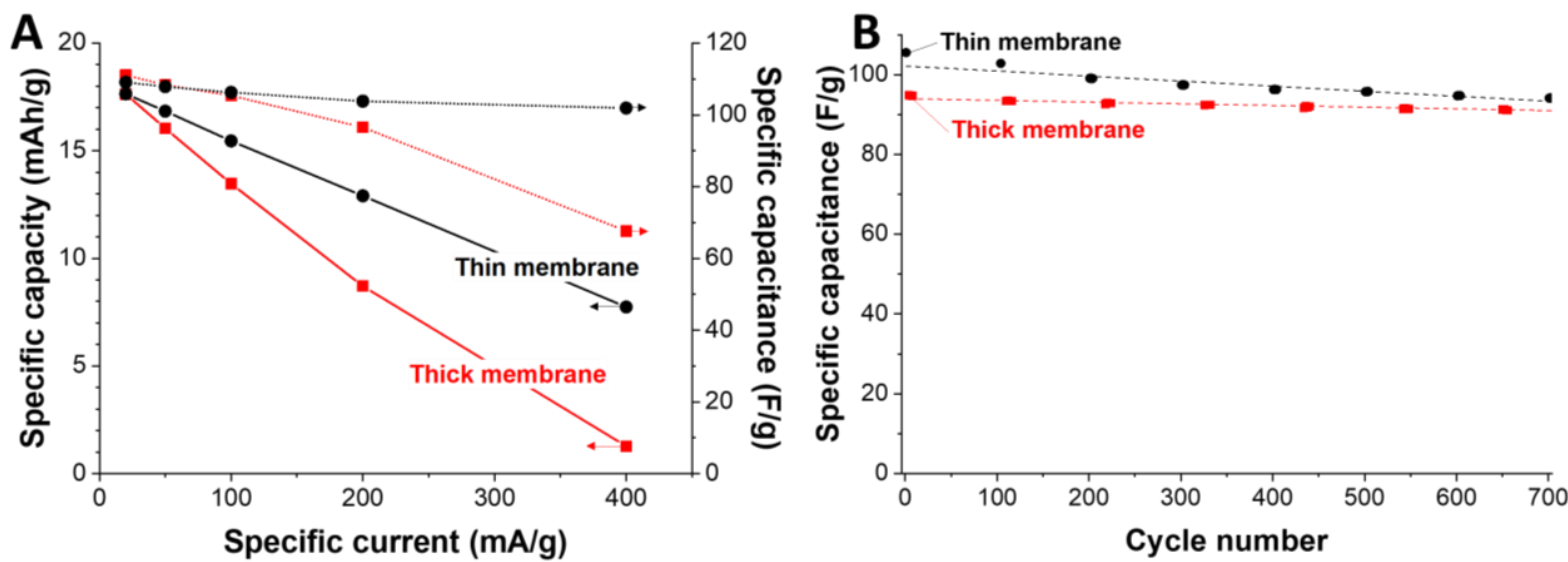

Figure S3: Electrochemical properties measured in a symmetric full-cell with thin and thick NASICON membranes using aqueous $1 \mathrm{M} \mathrm{NaCl}$ as the electrolyte. (A) Rate handling performance measured by galvanostatic charging and discharging in the cell voltage range of 0-1.2 V. (B) Galvanostatic charge/discharge performance stability at $200 \mathrm{~mA} / \mathrm{g}$ in the cell voltage range of 0-1.2 V.

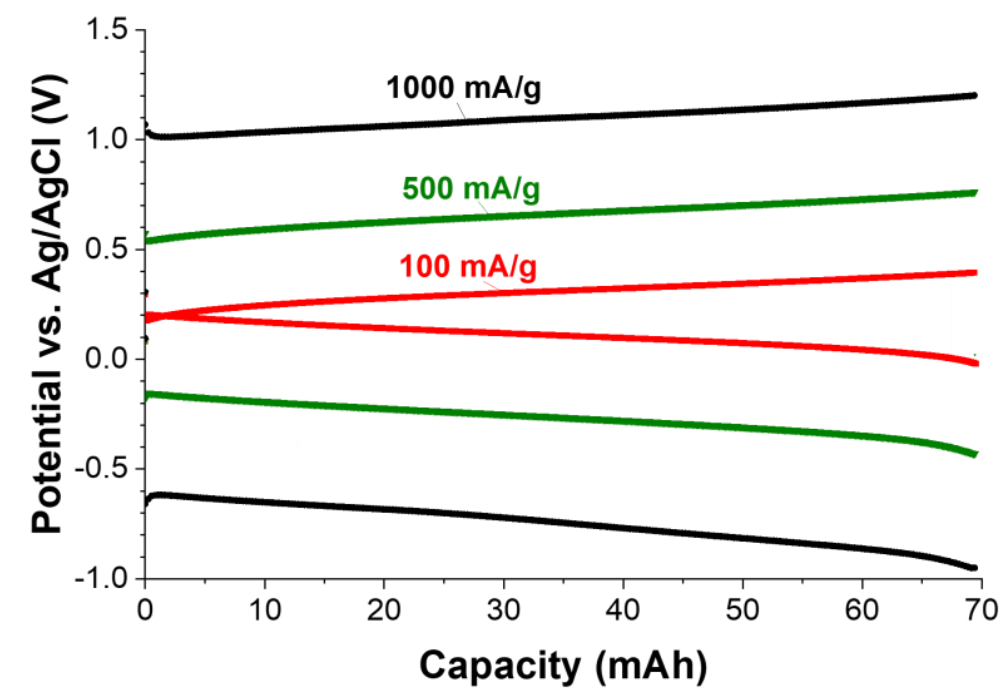

Figure S4: Potential profiles of the working electrode in the desalination cell obtained at specific current in a range of $100-1000 \mathrm{~mA} / \mathrm{g}$. 


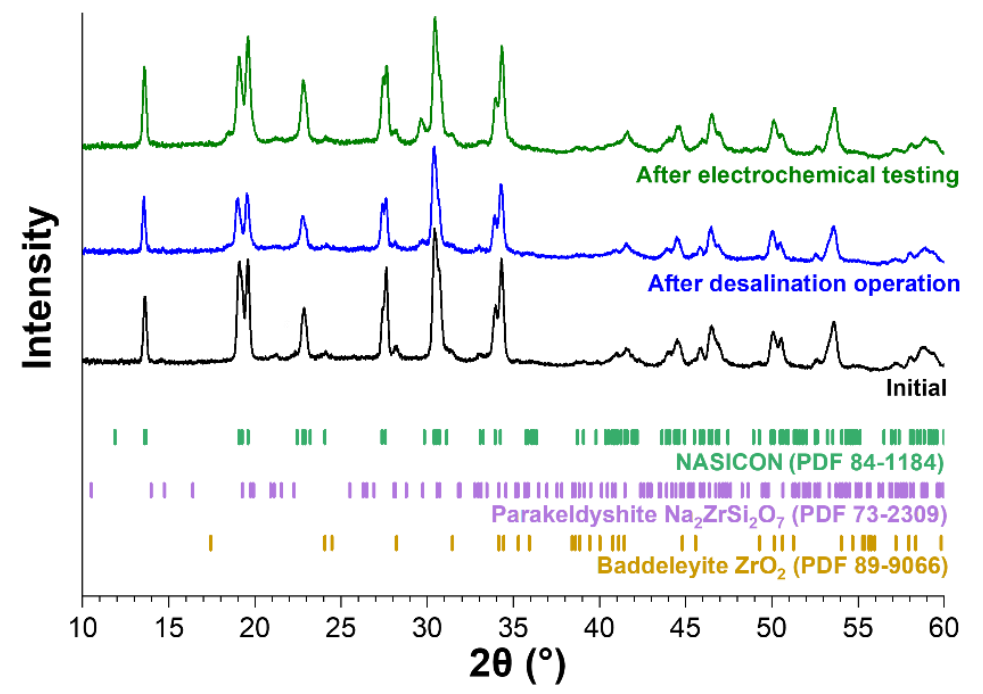

Figure S5: X-ray diffractograms of the NASICON membranes after long-term desalination and electrochemical testing. As a reference, the diffractogram of the initial membrane is shown, too. 
Table S1: Results of Rietveld fitting of the X-ray diffraction data. DE: desalination experiments. EC: initial electrochemical benchmarking.

\begin{tabular}{|c|c|c|c|c|c|c|c|c|c|c|c|c|c|c|c|c|c|}
\hline & \multicolumn{5}{|c|}{ NASICON (PDF 84-1184) } & \multicolumn{7}{|c|}{ Parakeldyshite $\mathrm{Na}_{2} \mathrm{ZrSi}_{2} \mathrm{O}_{2}$ (PDF 73-2309) } & \multicolumn{5}{|c|}{ Baddeleyite $\mathrm{ZrO}_{2}$ (PDF 89-9066) } \\
\hline & $a(A)$ & b (A) & $c(A)$ & $\begin{array}{c}\text { beta } \\
\left({ }^{\circ}\right)\end{array}$ & $\begin{array}{c}\text { Amount } \\
\text { (wt\%) }\end{array}$ & a (A) & b (A) & $c(A)$ & $\begin{array}{c}\text { alpha } \\
\left({ }^{\circ}\right)\end{array}$ & $\begin{array}{c}\text { beta } \\
\left({ }^{\circ}\right)\end{array}$ & $\begin{array}{c}\text { gamma } \\
\left({ }^{\circ}\right)\end{array}$ & $\begin{array}{c}\text { Amount } \\
\text { (wt\%) }\end{array}$ & a (A) & b (A) & $c(A)$ & $\begin{array}{c}\text { beta } \\
\left({ }^{\circ}\right)\end{array}$ & $\begin{array}{c}\text { Amount } \\
\text { (wt\%) }\end{array}$ \\
\hline Initial & 15.6619 & 9.0626 & 9.2203 & 123.79 & 89 & 6.5890 & 8.8455 & 5.4377 & 92.00 & 93.38 & 71.24 & 8 & 5.1526 & 5.2022 & 5.3476 & 99.01 & 3 \\
\hline $\begin{array}{l}\text { Soaked } \\
\text { in } \mathrm{Nal}\end{array}$ & 15.6495 & 9.0588 & 9.2193 & 123.72 & 90 & 6.5741 & 8.8165 & 5.4375 & 91.10 & 93.35 & 71.40 & 7 & 5.1627 & 5.1614 & 5.3563 & 99.18 & 2 \\
\hline $\begin{array}{l}\text { Soaked } \\
\text { in } \mathrm{NaCl}\end{array}$ & 15.6574 & 9.0583 & 9.2166 & 123.79 & 91 & 6.5820 & 8.8453 & 5.4374 & 92.02 & 93.39 & 71.27 & 7 & 5.1563 & 5.2048 & 5.3384 & 99.01 & 2 \\
\hline After DE & 15.6357 & 9.0587 & 9.2183 & 123.69 & 88 & 6.5764 & 8.8344 & 5.4407 & 91.38 & 93.48 & 71.33 & 9 & 5.1706 & 5.1655 & 5.3537 & 99.13 & 3 \\
\hline After EC & 15.6360 & 9.0563 & 9.2037 & 123.69 & 91 & 6.5695 & 8.8053 & 5.4394 & 91.30 & 93.47 & 71.20 & 6 & 5.1821 & 5.1708 & 5.3328 & 99.21 & 3 \\
\hline
\end{tabular}

